\title{
Cyber Teaching Optimization Based on Micro-blog Communication
}

\author{
Bo ZHANG \\ School of Marxism, China University of Geoscience, Beijing, China. \\ zznu001@139.com
}

Key words: cyber teaching optimization, online communication, micro-blog

\begin{abstract}
This research is a feedback survey which is delivered after the implementation of a teaching reform project. We managed to teach and guide students to make good use of self-media platforms to optimize their learning. With the statistics collected, we carried out a thorough evaluation of the effect and intangible value of the micro-blog learning model by using comparative method. With the help of self-media like micro-blog, we found that students had improved their thoughts and become more rational. We believe that the learning model is effective for the dissemination of talents in the new media era, and it can be used for reference in future study.
\end{abstract}

\section{Introduction}

The era of micro communication and self-media is coming with a new way of teaching and learning, and with the reform and innovation of media technology, media literacy and subject knowledge. At the same time, students tend to have a stronger personality than their seniors, the traditional classroom teaching model has become more and more difficult to meet their requirement, and it has been a huge challenge for all teachers to face with or without intention.

Professor Negroponte believed that in twenty-first Century, the community formed by the network users will become the mainstream of everyday life [1], and his prophecy has come true, more and more researches concerning from distant learning [2] to cyber studying have been delivered. Social media, which allows users to communicate with each other and share data tools, network community mainly, refers to micro-blog, SNS, forum, blog, QQ as the representative of social media gathered in groups of virtual community or virtual community. They provide people with cyber space to communicate and platforms for sharing information and learning.

In foreign countries, more and more universities use social media for distance education and network teaching, the characteristics and patterns of the network learning community are investigated.

As a new way of learning and teaching, MOOC, now has been proved to be popular in many countries including China. Universities in China have been involved a lot in MOOC, and many teachers and students gain their success online. There is a special part of MOOC, known as discussion online [3], as for now, this part is not run quite well in China for many reasons, our research is to use micro-blog and other mobile social media [4] to enhance this part and really make MOOC more effective in future study. There are some teachers have tried to use Facebook for cyber learning for assisting the traditional classroom teaching [5]. With the combination of micro-blog and other online apps and information technology, we try to find a better solution for fusion of tradition class and cyber study.

This study is a teaching reform of the network learning community based on self- media like micro-blog. In practice, the aim of the study is to discuss the feasibility of the network teaching in the teaching of the course of "Ideological and Moral Cultivation and legal basis" and the use of micro-blog in the process of College Students' learning. Students use modern network technology to carry out the implement of tradition class and online discussion on the course, and we expect to involve micro-blog to future MOOC experiment. From September 2015 to December 2015, we carried out the practice in four classes of our university. 


\section{Subjects and Methods}

\section{Cyber Learning Group Construction}

We selected four project experimental classes, a total of 121 student, divided into ten network learning community groups (respectively named as group 1 to group10), each group had ten to eleven students and one group leader for daily management of the group, each member of the groups must have their own micro-blog together with the members of the group sit in line in tradition classroom for convenient organization and a network learning community.

Each member should pay attention to the teacher's micro-blog before and after the tradition teaching. Teachers should give topics concerning the teaching material, and students were asked to post their opinions before and after the tradition teaching by both thumbs up or comments. Teachers should collect data for topic analysis and organization of the teaching process.

\section{Online Discussion and Classroom Debate}

The establishment of the micro-blog learning community should comment in the topics posted in teacher's micro-blog at least once a week or more as students wish. By the guidance of teacher, each group should form one point of the topic and fight against other angles both online and in classroom, students who could not make up their mind would be allowed to keep thinking and support others by click thumbs up in micro-blogs. After three days of online comment, teachers will collect opinions from the comments, and choose the most supported ones and least to carry out further debate in classroom by arranging face to face confrontation of the students.

Some professors had carried out experiments of blended environment teaching [6], with the help of micro-blog; we are trying to make more contribution towards blended learning model. During the classroom debate, teacher will use bullet screen for all students to express their opinions as the debate going on. Students involved in debate allowed to ask help from his group and his group's $h$ performance will affect all members' grade of the course. Teacher's work is to guide the debate to the teaching goal of the topic and record each performance of students involved for further investigations.

\section{Methods}

Based on the index of the frequency and the length of using and the number of active people, etc., we have proceed the quantify statistics calculation to feedback data, collected from both the online groups and the face to face questionnaire of all students involved.

To achieve the effective results, we turn to ask students cast an anonymous vote online to examine whether the teaching goal been fulfilled or not, and ask teachers to deliver a survey report.

We expect that the effect of the implementation of the network learning community is not only quantified, tangible, but also withstand the examination of time and space.

The results of the study were also assessed by the participant observation and in-depth interview survey methods to investigate the learning experience of selected twenty community members from both active and inactive of all the ten groups. We have also carried out a close and longtime observation to all participants.

\section{Results}

\section{The use of Micro-blog}

Micro-blog is a simple and convenient platform, the information is open and open, and the speed of communication is fast. $86.5 \%$ of all participants think that it is very practical for them to use micro-blog as an assist tool to enhance their understanding towards the theme of the subject. With text, video, sound, pictures and other shapes visual display, we find that micro-blog content meet the need of the researchers' hope that the use of micro-blog could improve both the teaching and learning. 
The survey show the results that before the implementation of the project, only $9.6 \%$ of the students often use micro-blog for news reading, and now has been raised to $52.3 \%$.

Micro-blog users can add attention to each other, and also pay attention to people all around world, that can provide much more risks and opportunities for teachers to enhance their teachings. The interaction of information between the person and the person concerned can be a pair of multimodal, which is an ideal virtual teaching model, can be very well used by teachers. After the post, students passively received the information, and the teachers can also choose to pay attention to the students to achieve the teaching supervision. The survey found that only a few students often pay attention to teachers' micro-blog, most students are passively received the teacher's micro-blog information.

\section{The Accomplishment of the Model}

From the feedback data including questionnaires every week in the teaching period, results of every vote after discussion, we managed to explain the improvement from items of "interest level”, "self-learned online involvement", "improvement comparison between pre-class and post-class", "communication skill improvement”, “team work spirit improvement”, etc..

Table 1 percentage of improvement from 10 groups

\begin{tabular}{|c|c|c|c|c|c|c|c|c|c|c|}
\hline & Group1 & $\begin{array}{c}\text { Group } \\
2\end{array}$ & Group3 & Group4 & Group5 & $\begin{array}{c}\text { Group } \\
6\end{array}$ & Group 7 & $\begin{array}{c}\text { Group } \\
8\end{array}$ & $\begin{array}{c}\text { Group 9 } \\
\text { Group } \\
10\end{array}$ \\
\hline Interest level & $75 \%$ & $73 \%$ & $68 \%$ & $69 \%$ & $76 \%$ & $75 \%$ & $78 \%$ & $79 \%$ & $65 \%$ & $81 \%$ \\
\hline $\begin{array}{c}\text { Involvement of } \\
\text { self-learned } \\
\text { online }\end{array}$ & $56 \%$ & $52 \%$ & $51 \%$ & $44 \%$ & $57 \%$ & $69 \%$ & $67 \%$ & $71 \%$ & $56 \%$ & $59 \%$ \\
\hline $\begin{array}{c}\text { Improvement of } \\
\text { comparison } \\
\text { between } \\
\text { pre-class and } \\
\text { post-class }\end{array}$ & $87 \%$ & $97 \%$ & $90 \%$ & $84 \%$ & $88 \%$ & $87 \%$ & $81 \%$ & $84 \%$ & $85 \%$ & $91 \%$ \\
\hline $\begin{array}{c}\text { Improvement of } \\
\text { communication } \\
\text { skills }\end{array}$ & $57 \%$ & $47 \%$ & $41 \%$ & $61 \%$ & $46 \%$ & $51 \%$ & $59 \%$ & $63 \%$ & $53 \%$ & $59 \%$ \\
\hline $\begin{array}{c}\text { Improvement of } \\
\text { team work spirit }\end{array}$ & $66 \%$ & $61 \%$ & $49 \%$ & $57 \%$ & $53 \%$ & $46 \%$ & $71 \%$ & $55 \%$ & $63 \%$ & $69 \%$ \\
\hline $\begin{array}{c}\text { No } \\
\text { improvement }\end{array}$ & $9 \%$ & $11 \%$ & $16 \%$ & $15 \%$ & $13 \%$ & $11 \%$ & $10 \%$ & $19 \%$ & $9 \%$ & $16 \%$ \\
\hline
\end{tabular}

Refer with: Table 1, From the item "interest level”, we can find that most participants have great interest in using micro-blog for cyber studying, which means we can use virtual platform in future work without worrying about participant degree.

From the item "involvement of self-learned online", there are some not very optimistic percentage within, so we have carried out an in-depth interview on some inactive members from group 4, and it turned out that are not interested in any forms of cyber study and treat them as wasting time, and this left us more work to involve these participants in future study.

From the item "improvement of comparison between pre-class and post-class", even the ones who are not interest in micro-blog study have to admit they have been improved a lot and have a great change of view towards the teaching materials, and that is vital important for the course "Ideological and moral cultivation and legal basis".

From the item "improvement of communication skills", we find out that even with great interests, students are tend to avoid using studying app in daily communication.

From the item "improvement of team work spirit", we find out that group discussion and debate make participants realize the importance of team work, which is the core value of collectivism. In traditional class, it is difficult for teachers to illustrate the key just by words and phrases. 


\section{Summary}

Through investigation, we found that there were three problems for enlightenment to further the cyber teaching.

1. Is it sustainable to use micro-blog in future teaching?

In general, with the help of micro-blog, college students' willing to express themselves have been greatly enhanced, but we have to consider the service life of this self-media platform in the same time. As the upgrading of these kinds of software, we have to make our teaching more sustainable, that is to say, we need to make sure the teaching model be effective not just on micro-blog, but also be applicable to other software.

2. What is students' most interest in cyber learning?

College students' care about the cyber learning is related to their personal interests, such as professional knowledge 、 personal habits 、 entertainment, etc. We have to study more about their special needs and make detailed plans for each and every one of them if necessary to guarantee the effectiveness of the course.

3. What are the effective ways of making all students involve?

When college students are under supervision of teachers, it is difficult to tell whether they are truly into the teaching process, because they are willing to show positive to get better grade. After accomplishing one period of the practice, we intend to keep focusing on former participants while on new ones to make sure the continuance of our reform, and to make sure the process be examined by long term. Only in this way, we can try to make all students involve the program, not just temporarily in one particular period.

\section{Acknowledgement}

This research was financially supported by the key subject of the educational reform project of China University of Geosciences (Beijing).

\section{References}

[1] Negroponte N, Harrington R, Mckay S R, et al. Being Digital [J]. Computers in Physics, 1995, 11(3):261-270.

[2] Thoms B, Eryilmaz E. How media choice affects learner interactions in distance learning classes [J]. Computers \& Education, 2014, 75(3):112-126.

[3] Knox J. Digital culture clash: "massive" education in the E-learning and Digital Cultures MOOC[J]. Distance Education, 2014, 35(2):164-177.

[4] Ciampa K. Learning in a mobile age: an investigation of student motivation [J]. Journal of Computer Assisted Learning, 2014, 30(1):82-96.

[5] Lampe C, Wohn D Y, Vitak J, et al. Student use of Facebook for organizing collaborative classroom activities[J]. International Journal of Computer-Supported Collaborative Learning, 2015, 6(3):329-347.

[6] Ekwunife-Orakwue K C V, Teng T L. The impact of transactional distance dialogic interactions on student learning outcomes in online and blended environments[J]. Computers \& Education, 2014, 78(259):414-427. 